\title{
EXPERIMENTAL STUDY ON FLEXURAL BEHAVIOR OF PRESTRESSED AND NON-PRESTRESSED TEXTILE REINFORCED CONCRETE PLATES
}

\author{
Nguyen Huy Cuong ${ }^{*}$, Ngo Dang Quang ${ }^{1}$ \\ ${ }^{1}$ University of Transport and Communications, No 3 Cau Giay Street, Hanoi, Vietnam.
}

\author{
ARTICLE INFO \\ TYPE: Research Article \\ Received: 12/12/2019 \\ Revised: 06/01/2020 \\ Accepted: 20/01/2020 \\ Published online: 31/01/2020 \\ https://doi.org/10.25073/tcsj.71.1.5 \\ * Corresponding author \\ Email: nguyenhuycuong@utc.edu.vn; Tel: 0989832425
}

\begin{abstract}
The application of prestressing steel is restricted in highly corrosive environment area due to corrosion of prestressing steel, which leads to reduction in strength and it may cause sudden failure. Carbon textile is considered as an alternate material due to its corrosive resistance property, high tensile strength and perfectly elastic. In this study, an experimental investigation was carried out to study the flexural behavior of prestressed and non-prestressed carbon textile reinforced concrete plates. This study also focuses on the influences of textile reinforcement ratios, prestress grades on the flexural behavior of carbon textile reinforced concrete (TRC). Fifteen precast TRC plates were tested, of which six were prestressed to various levels with carbon textile. The obtained results show that prestressing of textile reinforcement results in a higher load bearing capacity, stiffness and crack resistance for TRC plates.
\end{abstract}

Keywords: textile reinforced concrete, prestressed plates, carbon, flexure.

(C) 2020 University of Transport and Communications

\section{INTRODUCTION}

Textile reinforced concrete (TRC) is a new innovative materials, which uses mesh-like reinforcements in combination with a fine-grained concrete. Due to its non-corrosive textile reinforcement, made of alkali-resistant glass or carbon fibers, a minimum concrete cover is necessary to transfer bond stresses from the reinforcement to the concrete. High strength, ductility and non-corrosiveness textile reinforcements make TRC very suitable for 
construction of thin-walled, light weight shell structures [1]. This material can be also used in the retrofitting of existing structures as repair layer with not only a strengthening, but also a protective function to prevent corrosion problem in RC structures. Today, tensile strength up to $3000 \mathrm{MPa}$ can be achieved depending on the fiber material. However, the high strength property of textile reinforcements can not be effectively utilized due to concrete performances [2]. Concrete performs well under compression but will be easily cracked when subjected to tension, and reinforcement becomes effective only after cracking occurs. In this case, the low reinforcement ratio and high strength of textile reinforcement, together with a lower modulus of elasticity, is disadvantageous. The first crack that forms becomes rather wide and subsequent cracks appear, resulted in a less stiff structure.

In order to utilize the true tensile strength of the textile and make it act in a more active way, the reinforcements could be prestressed before installed onto the concrete member. This new approach is expected to increase the cracking load of TRC structures, thus the serviceability in the uncracked state is improved. On the other hand, the textile reinforcements are behaving linearly elastic until rupture. This property is particularly suitable for prestressing technique.

Since TRC is still a relatively new construction material, which has not yet been standardised, little research reported in this area, especially for the prestressed TRC structures. Krüger [2] analysed the bond behaviour of textiles used for prestressing in fine grained concrete under different conditions and reported that, the use of AR glass textiles as a prestressing element is not practical due to creep and a low static fatigue limit. Peled [3] found that pre-tensioning of fabrics and the time at which the tension is removed can significantly influence the performance of the composite depending on yarn properties, mainly the viscous-elastic properties, and fabric geometry. Yunxing [6] investigated the influences of textile layers, prestress levels and short steel fibers on the tensile behavior of carbon TRC. It was found that evident increases in first-crack stress and tensile was observed with increasing prestress grades. Therefore, the serviceability limit states of TRC composites can be extended by exerting a prestressing force on the textiles. Yunxing [7-8] also studied the influences of the number of textile layers, prestress grades of textile on the flexural behavior of basalt and carbon textile-reinforced concrete plate. The presence of prestress or steel fibres improved first-crack and ultimate stresses of the TRC specimen. In comparison with the first-crack stress, a more pronounced enhancement in the ultimate stress was achieved by the addition of steel fibres. Reinhardt [4-5] dealt with flexural bahavior of carbon and glass TRC plates and reported that the impregnated carbon is very suitable for prestressing. The largest effect of prestressing is that the initial strain of a fabric is anticipated and that deflection and crack width after first cracking is minimized.

This present paper aims to investigate the influence of the number of textile layers, prestress grades, on the flexural behavior of carbon TRC plates. The four-point bending tests were employed. Based on the tests, the load-deflection relationship, cracking mechanisms and failure modes of each experimental case are presented and analyzed.

\section{SPECIMENS AND TEST DESCRIPTION}

\subsection{Test specimens}

In this study, all the carbon TRC specimens had the same dimension of $900 \mathrm{~mm}$ (length) x $150 \mathrm{~mm}$ (width) x $40 \mathrm{~mm}$ (depth). Two sets of TRC specimens were tested, corresponding 
to the non-prestressed and prestressed plates. In the first set, the TRC plates have different number of carbon textile layers, vary from $1 \div 3$ layers. In the $2^{\text {nd }}$ set, six specimens were applied by prestressing force, corresponding to $50 \%$ and $70 \%$ tensile force of textile layer in uniaxial test. The initial prestressing values were selected based on the recommendations of conventional prestressed reinforced concrete theory. For each experimental case, three nominally identical specimens were manufactured. Specimens were named following the notation $\mathrm{P} x \mathrm{~L} y \mathrm{~N} z$, where $x=$ prestressed level in percentage, $y=$ number of textile layers, and $z$ $=$ specimen number. For example, the label P50L1N2 represents $2^{\text {nd }}$ specimen with 1 layer of carbon textile, which is applied by prestressing level of 50\%. The details information for each specimen is mentioned in Table 2.

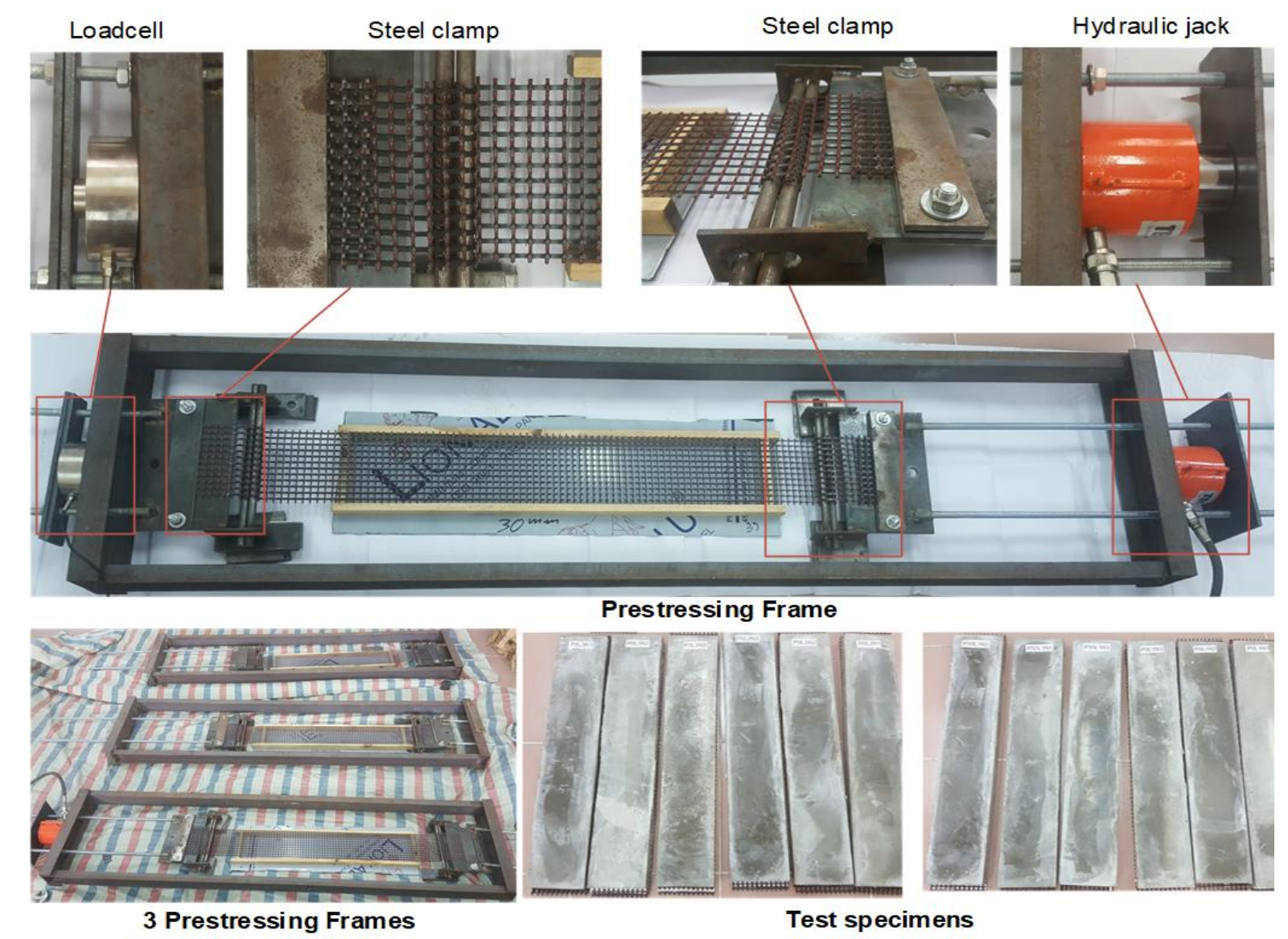

Figure 1. Prestressing frames and test specimens.

Figure 1 shows the prestressing frame as prepared for a uniaxial prestressing of textile. The clamps and the hydraulic jack can be seen in the frame with a total size of about $2.0 \mathrm{~m} \mathrm{x}$ $0.5 \mathrm{~m}$. The preparation process was initiated by fixing all the textiles on the prestressing frame at both ends of the device, textiles were wrapped around two smooth rollers, which were then placed in the steel clamp. Prestress was applied to the textiles by the hydraulic jack. The prestress was measured by the load cell fixed at the other end of the frame and recorded by a data acquisition system. After reaching the prescribed prestress value of the textiles, the chute at tension end was fixed by the adjusting nut. Subsequently, fine-grained concrete was mixed and directly poured into the mold. Then, the mixture was vibrated fully and the top surface was smoothed by using a metal spatula. The CTRC plates were covered with wet cloths after 
the matrix was initially set. The prestressed ones were allowed to harden for 14 days before releasing the pre-tension force. All the plates were then removed from their molds and cured until testing was performed after 28 days.

\subsection{Material properties}

The fine grained binder systems with a maximum grain size of $0.6 \mathrm{~mm}$ was specifically designed for application with carbon textile, was comprised of high-fineness cement binder. The high performance plasticizer and fly ash were added to achieve a very good flowing capability of the concrete in order to ensure a proper penetration of the small gaps of the fabrics. The fine grained concrete was mechanically characterized by testing six $40 \mathrm{~mm} \times 40$ $\mathrm{mm} \times 160 \mathrm{~mm}$ prisms. The obtained average flexural strength and average compressive strength at 28 days were equal to $6.95 \mathrm{MPa}$ and $47.5 \mathrm{MPa}$. The average flexural strength and compressive strength at 14 days (at the time of releasing prestressed force) were equal to 5.72 $\mathrm{MPa}$ and 38.7 MPa.
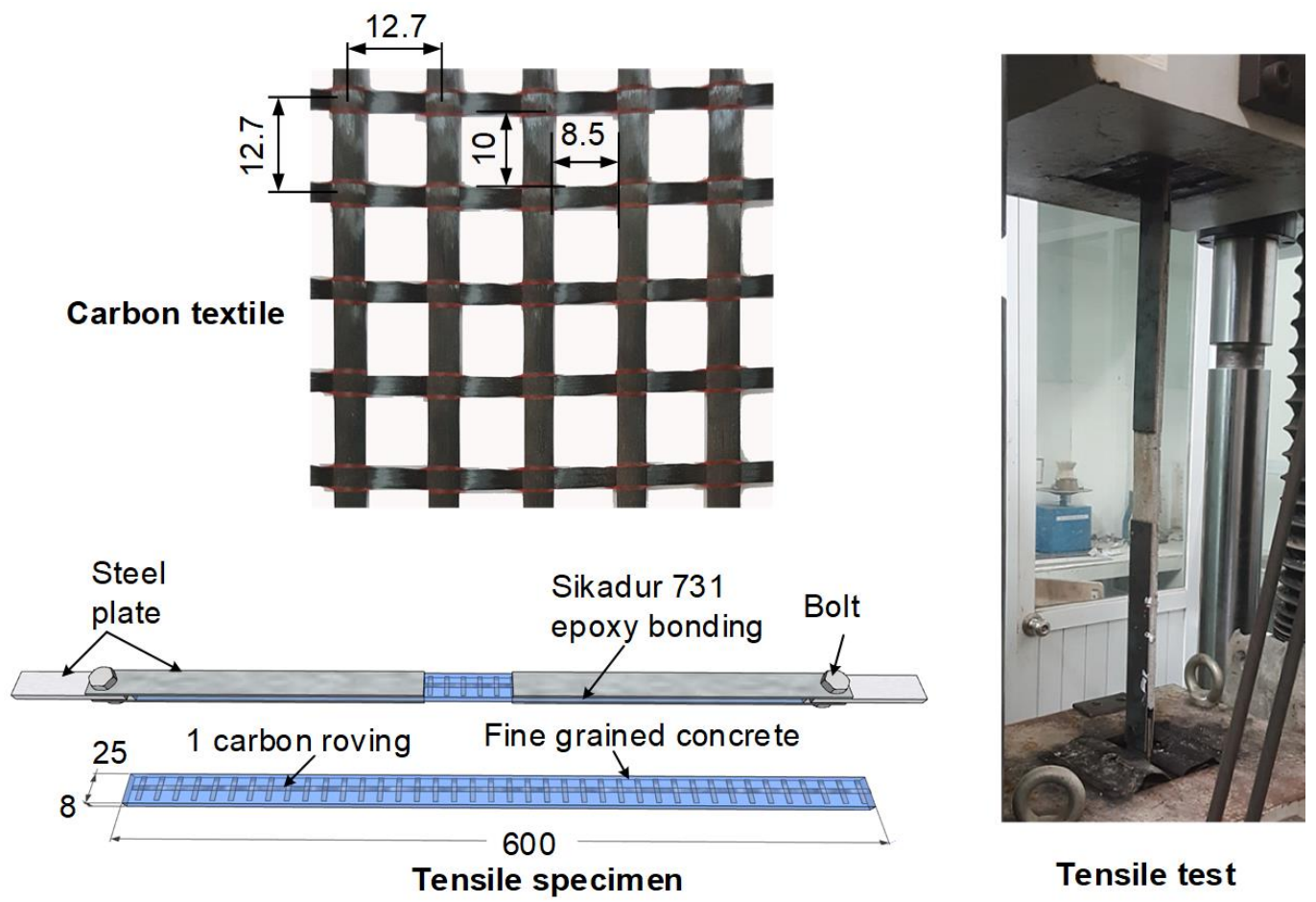

Figure 2. Carbon textile and TRC specimen for the uni-axial tensile test.

In this study, the carbon textile reinforcement SITgrid017 was made from V.FRAAS company (Germany). The carbon fiber yarns, having a count of 3200 tex, were processed in the warp and weft directions with a distance of approximately $12.7 \mathrm{~mm}$ between them. Each carbon roving consists of 48.000 fibers and has a cross sectional area of $1.808 \mathrm{~mm}^{2}$ (in both directions). A textile having a weight per unit area of roughly $578 \mathrm{~g} / \mathrm{m}^{2}$ was produced. The geometrical and mechanical characteristics are collected in Table 1. According to recommendation of RILEM TC 232-TDT [9], the tensile strength and elastic modulus of the fiber were measured by means of tensile tests on the uni-axial tensile specimens (Figure 2) and were equal to $2890 \mathrm{MPa}$, and $185 \mathrm{GPa}$, respectively. 
Transport and Communications Science Journal, Vol. 71, Issue 1 (01/2020), 37-45

Table 1. The geometrical and mechanical characteristics of SITgrid017 textile.

\begin{tabular}{cccccc}
\hline \hline & \multicolumn{2}{c}{ Geometric } & & \multicolumn{2}{c}{ Mechanical characteristics } \\
\hline $\begin{array}{c}\text { Roving } \\
\text { distance }[\mathrm{mm}]\end{array}$ & Rovings/m & $\begin{array}{c}\text { Meshsize } \\
{[\mathrm{mm}]}\end{array}$ & $\begin{array}{c}\text { Roving area } \\
{\left[\mathrm{mm}^{2}\right]}\end{array}$ & $\begin{array}{c}\text { Tensile } \\
\text { strength } \\
{[\mathrm{MPa}]}\end{array}$ & $\begin{array}{c}\text { Elastic } \\
\text { modulus } \\
{[\mathrm{GPa}]}\end{array}$ \\
\hline $12.7 \times 12.7$ & 78 & $10 \times 8.5$ & 1.808 & 2890 & 185 \\
\hline \hline
\end{tabular}

The bond behaviour between textile reinforcement - fine grained concrete is very important for the whole load bearing behaviour of the TRC structures. Based on the pull-out test recommended by Zulassung Z-31.10-182 [10], one-layer reinforced specimens measuring $300 \mathrm{~mm} \times 50 \mathrm{~mm} \times 8 \mathrm{~mm}$ with a predetermined crack is prepared. Per specimen, exactly one roving with embedding length of $l_{E, 0}=25 \mathrm{~mm}$ can be gradually pulled out from the fine grained concrete (Figure 3). The displacement-controlled pull-out tests were carried out with a loading rate of $1 \mathrm{~mm} / \mathrm{min}$. The average bonding strength between SITgrid017 textile and fine grained concrete was $18.8 \mathrm{~N} / \mathrm{mm}$ (force per length). Based on the tested results, the effective anchorage length of textile in fine grained concrete can be calculated as about $275 \mathrm{~mm}$.
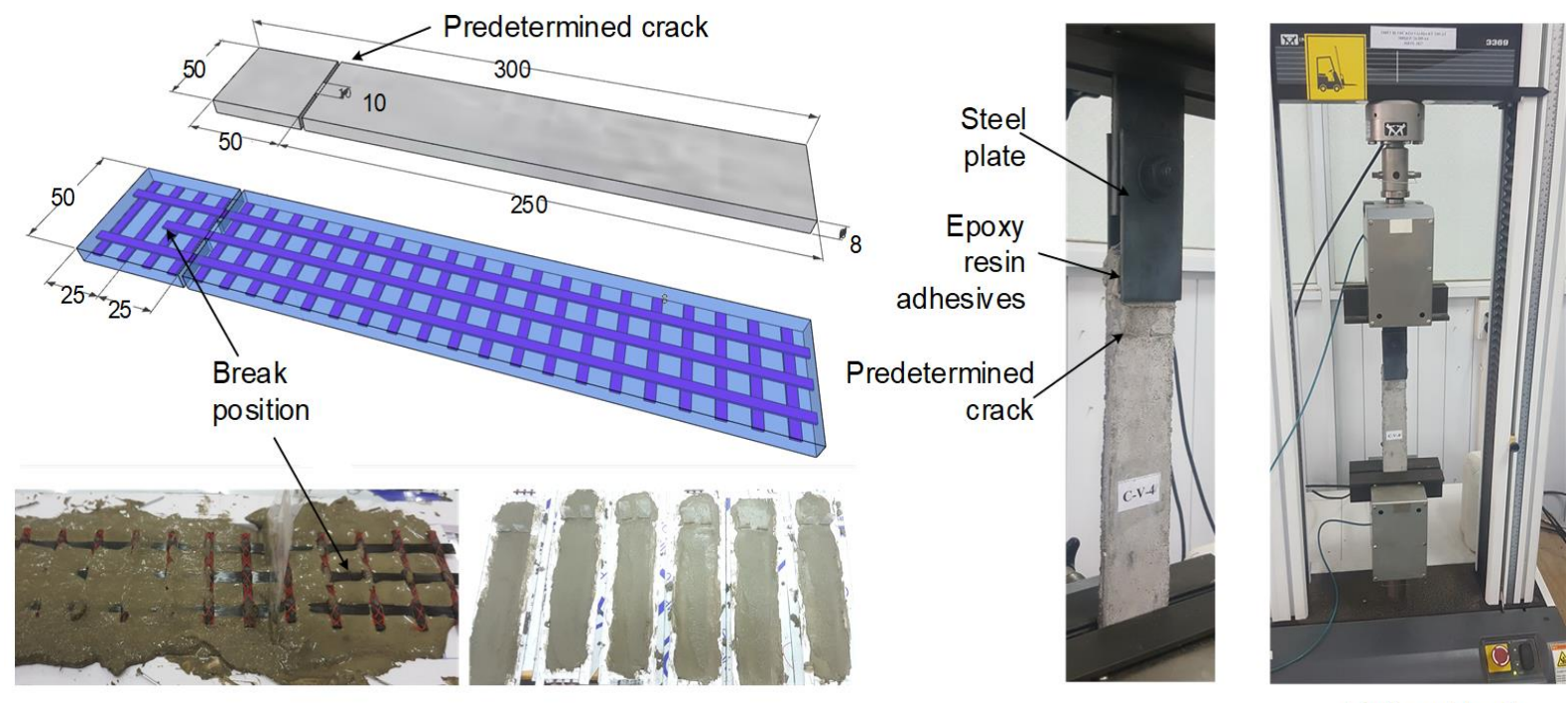

Pull-out test

Figure 3. Specimen for pull-out test.

\subsection{Test setup and instrumentation}

All the tests were conducted in the Structural Engineering Laboratory at University of Transport and Communications, Vietnam. Specimens were monotonically loaded with fourpoints bending, using displacement controlled method, with loading rate of $1 \mathrm{~mm} / \mathrm{min}$. The clear span of all the plates was kept constant at $450 \mathrm{~mm}$ and the shear span was $150 \mathrm{~mm}$. Schematic view and a view of the test setup are shown in Figure 4. A LVDT was installed on the bottom surface of the plate to measure its deflections during the test. Moreover, strain gages were used to record compressive and tensile strains concrete at upper and lower surfaces during the experiment. A computer based data acquisition system was used to record the load from the load cell, and the deflection from LVDT and the strain from strain gages. 


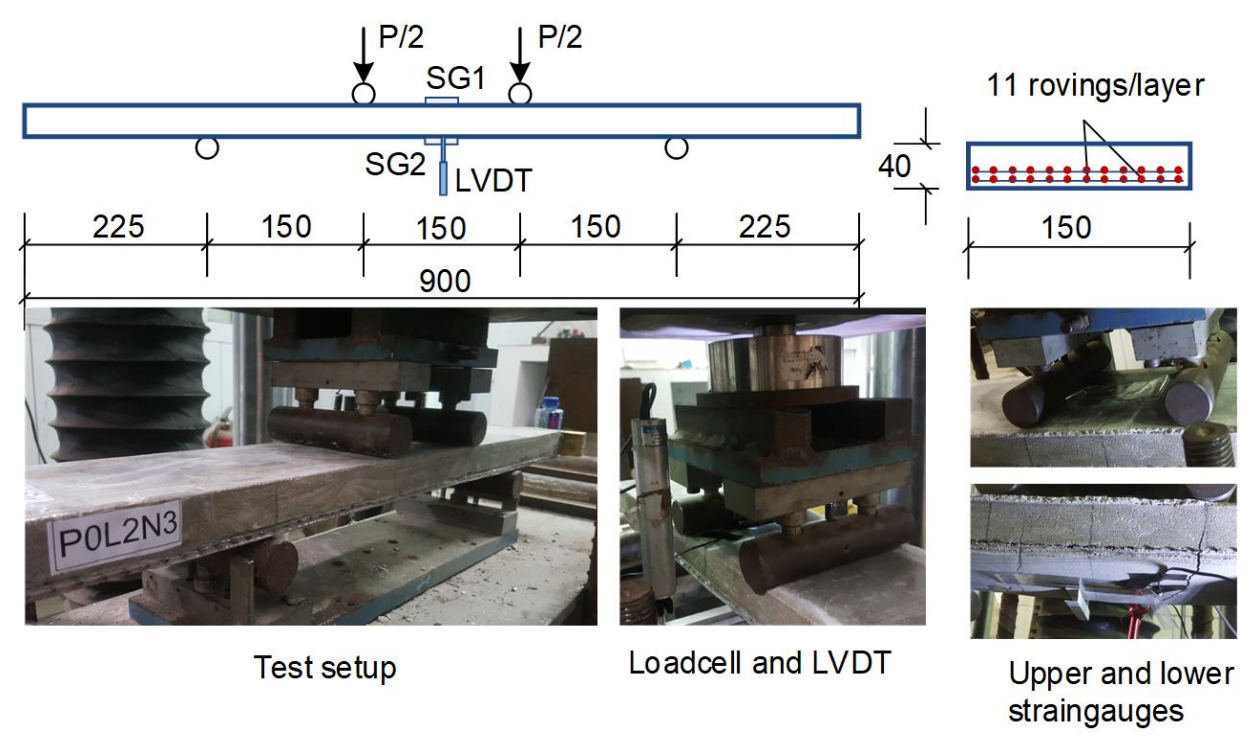

Figure 4. Test setup.

\section{TEST RESULTS}

The load versus deflection curves are presented as shown in Figure 5 and Figure 7 for all two sets. Table 2 shows a summary of the load - deflection in cracking and ultimate of all test specimens. In addition, failure modes and crack patterns of tested plates are illustrated in Figure 6. The experimental results showed that, the non-prestressed and prestressed plates with 1 textile layer failed due to rupture of the carbon textile (Figure 6-a). On the contrary, the non- prestressed plates with 2 and 3 layers of textile failed due to crushing of the concrete in the compression zone before rupture of the textile reinforcement (Figure 6-b).
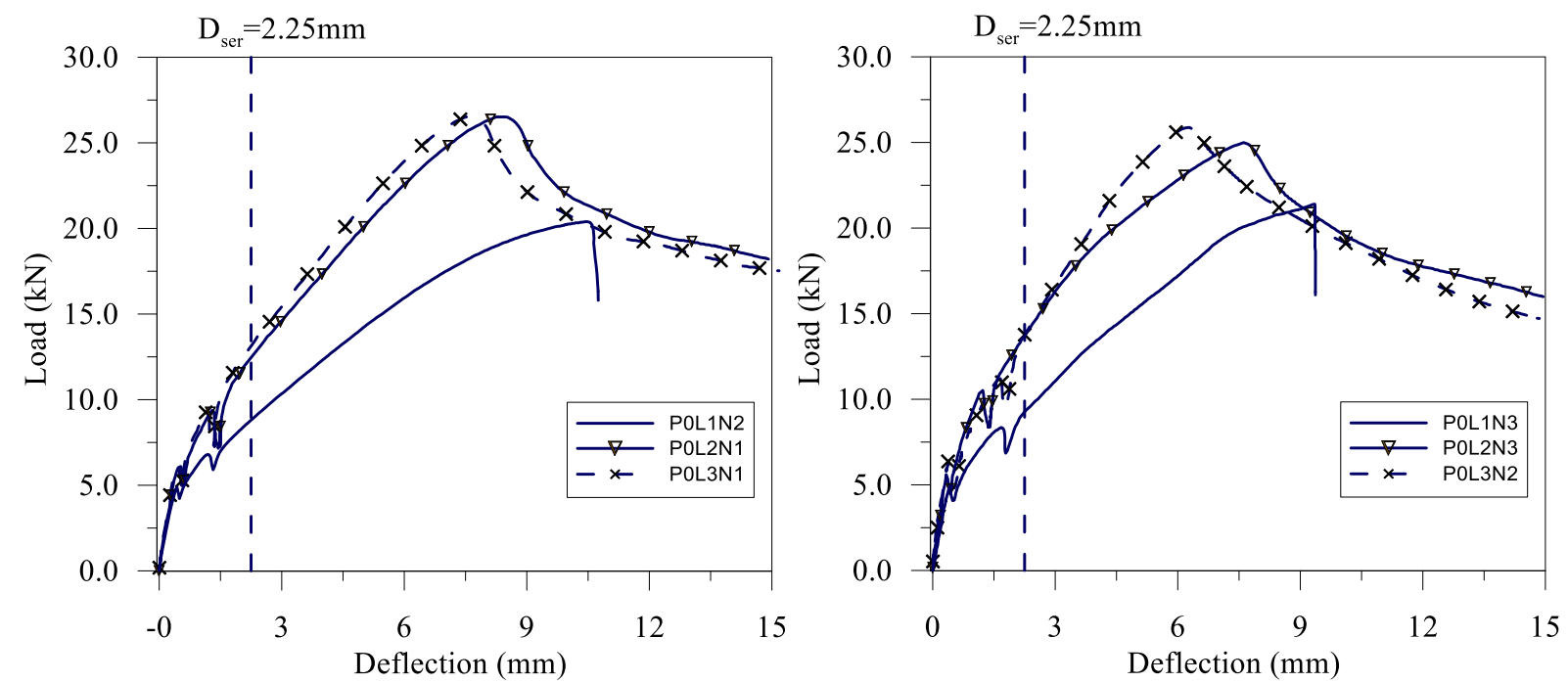

Figure 5. Load-displacement of Non-Prestressed Slabs.

Figure 5 compares the load-defection of non-prestressed plates with 1, 2 and 3 fabric layers. All plates show the similar load bearing behaviour in the first stages. The load deflection curves indicate a linear elastic behaviour, up to the point of first flexural crack appears, at a load level of $4 \div 6 \mathrm{kN}$. The average cracking loads in 2 and 3-layers plates are respectively 14 and $18 \%$ higher than those of 1 layer plates. Stiffness of the plates decreased after the first cracks, resulting in larger deflection, especially in 1-layer plates. Due to the 
bond between textile roving and fine-grained concrete, tensile stress was developed in the concrete, until the tensile strength of the fine-grained concrete is reached once more. With an increasing of the tension force, additional crack occurred in all types of tested plates. In 1layer plates, by a load increase, the rovings are strained up to their tensile strength. In this stage, the crack pattern was stabilized, no further cracks occur, but the biggest crack expanded larger. Then, the textile reinforcement was continuously broken, resulting the flexural failure mode with rupture of textile reinforcement. In contrast to 1-layer plates, the non-prestressed plates with 2 and 3 fabric layers exhibited the crushing of the concrete in the compression zone, at defection of around $7 \div 8 \mathrm{~mm}$. After the two and three-layers specimens reach their ultimate capacity (approximately $25.5 \mathrm{kN}$ ), their curves show a slow but constant decrease. This is due to the fact that the concrete could not carried the big compression force, and the concrete zone fails more and more. This also means that the full tensile capacity of the textiles cannot be used because of the weakness of the compression zone.

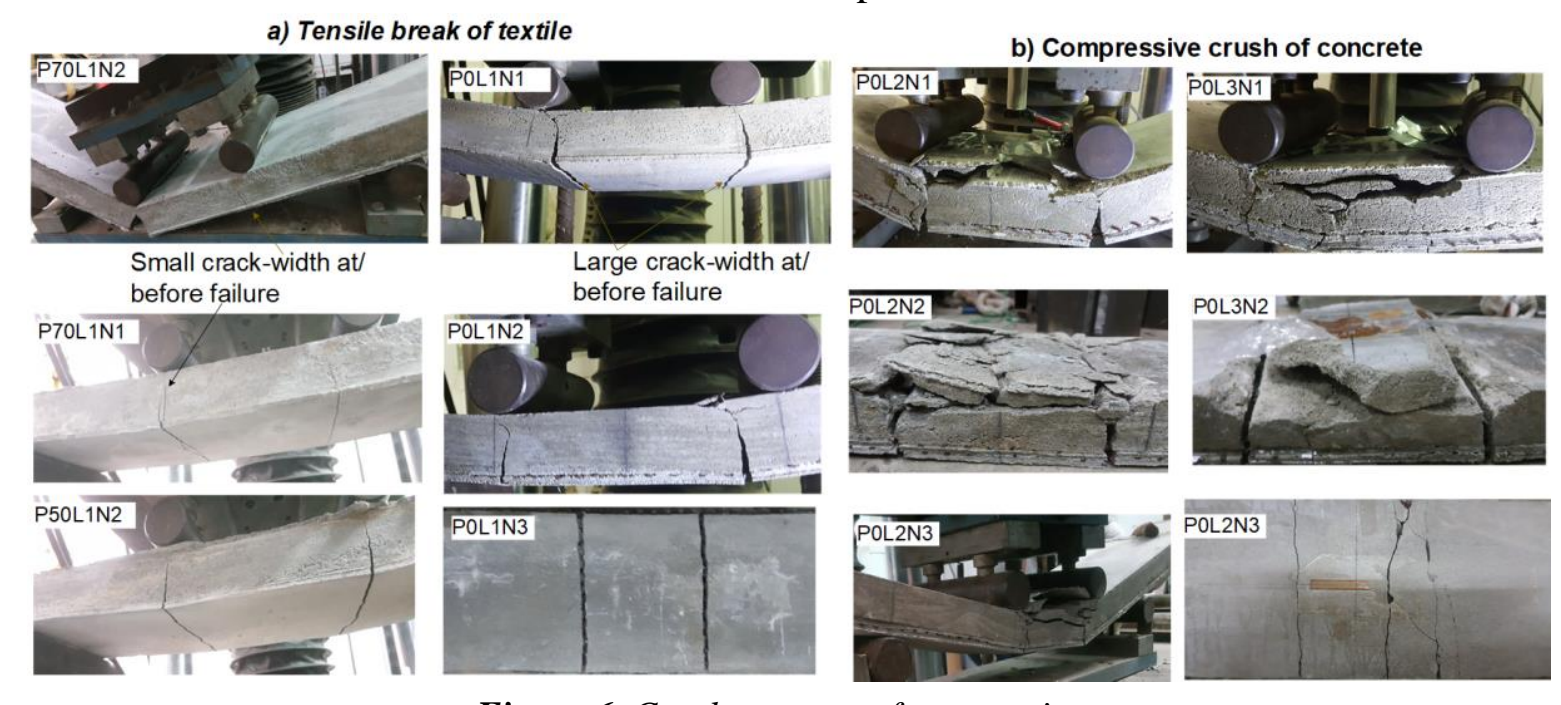

Figure 6. Crack patterns of test specimens.

Table 2. Load, deflection, and modes of failure comparison for all specimens.

\begin{tabular}{|c|c|c|c|c|c|c|c|c|c|}
\hline \multirow{2}{*}{ Set } & \multirow{2}{*}{ Plate } & \multicolumn{3}{|c|}{ Cracking } & \multicolumn{3}{|c|}{ Ultimate } & \multirow{2}{*}{$\begin{array}{c}\text { Failure } \\
\text { mode }\end{array}$} & \multirow{2}{*}{$\begin{array}{c}\text { Energy } \\
\text { dissi- } \\
\text { pation } \\
\text { (kN.mm) }\end{array}$} \\
\hline & & $\begin{array}{c}\mathrm{D}_{\mathrm{cr}} \\
(\mathbf{m m})\end{array}$ & $\begin{array}{c}\mathbf{P}_{\mathrm{cr}} \\
(\mathbf{k N})\end{array}$ & $\begin{array}{l}\mathbf{P}_{\text {cr,avg }} \\
(\mathbf{k N})\end{array}$ & $\begin{array}{c}\mathbf{D}_{\mathbf{u}} \\
(\mathbf{m m})\end{array}$ & $\begin{array}{c}\mathbf{P}_{\mathbf{u}} \\
(\mathbf{k N})\end{array}$ & $\begin{array}{l}\mathbf{P}_{\mathrm{u}, \mathrm{avg}} \\
(\mathbf{k N})\end{array}$ & & \\
\hline \multirow{9}{*}{$\begin{array}{l}\text { Set 1: } \\
\text { Non } \\
\text { pre- } \\
\text { stress }\end{array}$} & P0L1N1 & 0.43 & 5.50 & \multirow{3}{*}{5.28} & 9.36 & 21.40 & \multirow{3}{*}{20.51} & \multirow{3}{*}{$\begin{array}{l}\text { Textile } \\
\text { rupture }\end{array}$} & 16.29 \\
\hline & P0L1N2 & 0.43 & 5.48 & & 10.44 & 20.40 & & & 15.76 \\
\hline & P0L1N3 & 0.32 & 4.97 & & 10.34 & 19.75 & & & 16.43 \\
\hline & P0L2N1 & 0.53 & 6.10 & \multirow{3}{*}{6.02} & 8.25 & 26.41 & \multirow{3}{*}{25.36} & \multirow{3}{*}{$\begin{array}{l}\text { Concrete } \\
\text { crushing }\end{array}$} & 20.91 \\
\hline & P0L2N2 & 0.49 & 6.37 & & 8.17 & 25.38 & & & 19.35 \\
\hline & P0L2N3 & 0.33 & 5.60 & & 7.61 & 24.29 & & & 24.42 \\
\hline & P0L3N1 & 0.48 & 6.10 & \multirow{3}{*}{6.23} & 7.50 & 26.51 & \multirow{3}{*}{25.79} & \multirow{3}{*}{$\begin{array}{l}\text { Concrete } \\
\text { crushing }\end{array}$} & 24.05 \\
\hline & P0L3N2 & 0.38 & 6.37 & & 6.28 & 25.88 & & & 28.13 \\
\hline & P0L3N3 & 0.35 & 6.22 & & 7.25 & 24.99 & & & 23.96 \\
\hline \multirow{6}{*}{$\begin{array}{c}\text { Set 2: } \\
\text { Pre- } \\
\text { stress }\end{array}$} & P50L1N1 & 0.65 & 9.89 & \multirow{3}{*}{9.68} & 6.32 & 22.40 & \multirow{3}{*}{21.92} & \multirow{3}{*}{$\begin{array}{l}\text { Textile } \\
\text { rupture }\end{array}$} & 30.70 \\
\hline & P50L1N2 & 0.52 & 9.15 & & 6.78 & 22.11 & & & 31.57 \\
\hline & P50L1N3 & 0.63 & 10.11 & & 5.29 & 21.24 & & & 30.83 \\
\hline & P70L1N1 & 0.67 & 10.14 & \multirow{3}{*}{9.86} & 5.72 & 20.75 & \multirow{3}{*}{21.33} & \multirow{3}{*}{$\begin{array}{l}\text { Textile } \\
\text { rupture }\end{array}$} & 31.25 \\
\hline & P70L1N2 & 0.62 & 10.01 & & 4.92 & 21.69 & & & 34.04 \\
\hline & P70L1N3 & 0.53 & 9.44 & & 6.05 & 21.55 & & & 30.44 \\
\hline
\end{tabular}


Figure 7 represents the influences of prestressing grades on the bending behavior of TRC plates. The behavior of all prestressed specimens in Set 2 also presented a typical flexural failure mode, consisted of three stages namely: (a) the un-cracked stage, (b) the cracked stage and (c) the failure stage. The load was linear up to the initiation of the first flexural crack in pure bending span, followed by a non-linear behavior up to failure. The average first-crack load of the prestressed specimens increased by $83.3 \%$ and $86.7 \%$, respectively, compared with those of non-prestressed plates. Since the carbon textile has no plastic capacity, the TRC specimens failed when the reinforcements reach their tensile strength. All textile rovings were continuously broken in a brittle manner. Before breaking, there were no sign of compressive failure in top edge of TRC plates. It should be noted that, the effective of prestressing force grades (i.e. 50\% and 70\%) in cracks resistance is not much different.
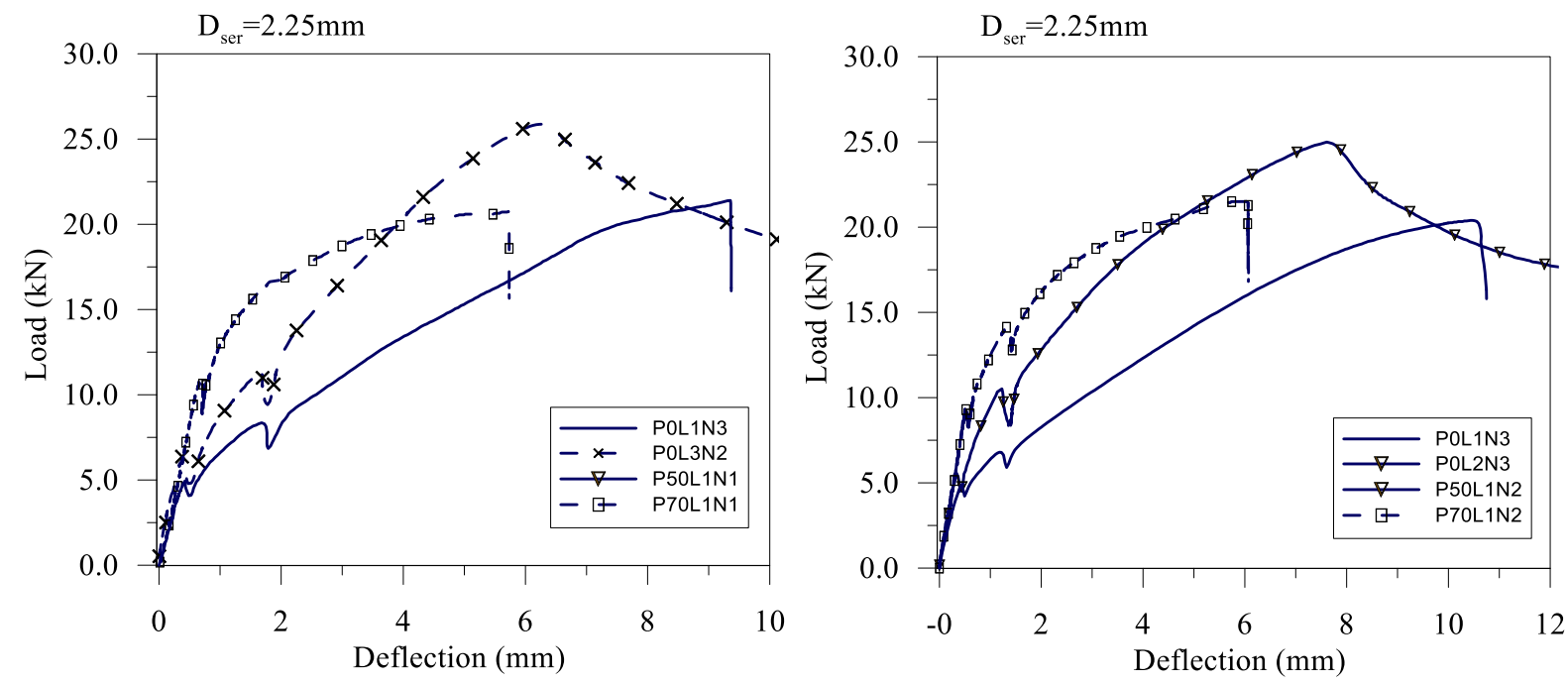

Figure 7. Comparison in load-displacement of Non-Prestressed and Prestressed Plates.

As shown in Table 2, prestress on the textile also slightly improved the bearing capacity of the TRC specimens and reduced the ultimate deflection. This can be explained by the complexity in tensile strength of textile rovings. The cracking of the concrete along the reinforcement leads to damage to the rovings and causes a decreasing strength of the component. The main effects responsible for this loss of strength are the lateral pressure and the bending stresses of the filaments at the crack edges [1]. As displayed in Figure 6-a, the cracks width in prestressed specimens before failure were much smaller than those in nonprestressed plates. The smaller cracks result in larger tensile strength of textile rovings. The comparison of data above indicated that the prestress on textile improved the first-crack and ultimate load capacities of the TRC specimens.

In order to apply TRC plates in construction, the deflection of these structure is one of the checks that should be performed for serviceability limit state design. In this test, the clear span of all the plates was kept constant at $450 \mathrm{~mm}$. This research also compares the load capacity and the energy dissipation of prestressed and non-prestressed plates at deflection level of 2.25 $\mathrm{mm}$, corresponding to 1/200 tested span. As can be seen in Figure 6 and Table 2, the average load in prestressed plates are respectively 85.6 and $91.2 \%$ higher than those of nonprestressed plates. Energy dissipation is estimated by the area under the load - defection curves. The average energy in prestressed plates are respectively 92 and $97 \%$ higher than those of non-prestressed plates with 1 fabric layer. The energy in 50\% prestressed plates is also $44 \%$ and $48 \%$ higher than those of non-prestressed plates with 2 and 3 fabric layers. 


\section{CONCLUSION}

In this paper, the influences of the number of textile layers and prestressing grades on the flexural behaviour of carbon TRC plate are investigated using four-point bending tests. For the non-prestressed plates, increasing the number of textile layers has a significant effect on overall behavior. With the increase in the number of textile layers, an improvement on the bearing capacity of the specimens and a smaller reduction in the flexural stiffness of the cracked specimens were observed. However, due to the limitation of the concrete compression capacity limits, the tensile strength of the textiles was not fully utilized. The failure mode of the specimen changed from textile rupture in 1 layer specimens to concrete crushing failure in 2 and 3 layers specimens. Prestress force on textile contributes to the evident improvement on first-crack load, but only slightly influences the ultimate tensile strength of TRC. The average first-crack load of the prestressed specimens increased by $83.3 \%$ and $86.7 \%$, respectively, compared with those of non-prestressed plates. However, it should be noted that, the effective of prestressing force grades (i.e. 50\% and 70\%) in cracks resistance is not much different. The presence of prestressing force also improved both load and energy dissipation of TRC plates at the limit deflection in serviceability.

\section{ACKNOWLEDGMENTS}

This research is funded by University of Transport and Communications (UTC) under the project code T2019-KTXD-07TD.

\section{REFERENCES}

[1] W. Brameshuber, Textile Reinforced Concrete. State-of-the Art Report of RILEM Technical Committee 201-TRC, 1st ed. Bagneux, vol. 36: RILEM Publications S.A.R.L., 2006.

[2] M. Kruger, H. W. Reinhardt, Bond behaviour of textile reinforcement in reinforced and prestressed concrete, Otto-Graf-Journal, 2001.

[3] A. Peled, Pre-tensioning of fabrics in cement-based composites, Cement and Concrete Research, 37 (2007) 805-813. https://doi.org/10.1016/j.cemconres.2007.02.010

[4] H. W. Reinhardt, M. Kruger, U. G. Christian, Concrete Prestressed with Textile Fabric, Journal of Advanced Concrete Technology, 1 (2003) 231-239. https://doi.org/10.3151/jact.1.231

[5] H. W. Reinhardt, M. Kruger, Prestressed Concrete Plates With High Strength Fabric, 6th RILEM Symposium on Fibre-Reinforced Concretes (FRC), 2004.

[6] D. Yunxing, M. Zhang, F. Zhou, D. Zhu, Experimental study on basalt textile reinforced concrete under uniaxial tensile loading, Construction and Building Materials, 138 (2017) 88-100. https://doi.org/10.1016/j.conbuildmat.2017.01.083

[7] D. Yunxing, X. Zhang, F. Zhou, D. Zhu, M. Zhang, P. Wei, Flexural behavior of basalt textilereinforced concrete, Construction and Building Materials, 183 (2018) 7-21. https://doi.org/10.1016/j.conbuildmat.2018.06.165

[8] D. Yunxing, X. Zhang, F. Zhou \& D. Zhu, M. Zhang, P. Wei, Flexural Behaviour of Carbon Textile-Reinforced Concrete with Prestress and Steel Fibres, Polymers, 10 (2018) 98 https://doi.org/10.3390/polym10010098

[9] RILEM Technical Committee 232-TDT, Recommendation of RILEM TC 232-TDT: test methods and design of textile reinforced concrete, May 2016.

[10] Zulassung Z-31.10-182, Gegenstand: Verfahren zur Verstärkung von Stahlbeton mit TUDALIT (Textilbewehrter Beton), Prüfstelle: DIBt, Antragsteller: TUDAG TU Dresden Aktiengesellschaft, 2015. 